\title{
Fractional Snow/Non-Snow Cover Mapping through Incorporation of Thermal Band in Snow Index Design
}

\author{
B. C. Yadav, Kamal Jain \\ Geomatics Engineering Group, Indian Institute of Technology, Roorkee, India \\ Email: bcyadav@outlook.com
}

How to cite this paper: Yadav, B.C. and Jain, K. (2017) Fractional Snow/Non-Snow Cover Mapping through Incorporation of Thermal Band in Snow Index Design. International Journal of Geosciences, 8, 1404-1416.

https://doi.org/10.4236/ijg.2017.811082

Received: October 10, 2017

Accepted: November 27, 2017

Published: November 30, 2017

Copyright $\odot 2017$ by authors and Scientific Research Publishing Inc. This work is licensed under the Creative Commons Attribution International License (CC BY 4.0).

http://creativecommons.org/licenses/by/4.0/

\begin{abstract}
Substantial development has been achieved in snow cover delineations through binary mapping techniques. Continuous efforts for development and institution of methodologies in fractional snow cover mapping are steadily conducted by the research communities. In this work, the attempts are driven towards the attainment of the same. MODIS (Moderate Resolution Imaging Spectroradiometer) images are worked upon Landsat 8 images under multivariate polynomial regression schemes utilizing corresponding count of pixels in a test region of Himachal Pradesh. $11.00 \mu \mathrm{m}$ centered waveband is employed to develop a scheme for snow mapping followed by a qualitative and quantitative comparison with NDSI and S3 snow index where the values of correlation coefficient between fractional snow cover and index values have been obtained as $77.04 \%, 78.82 \%$ and $85.15 \%$ for NDSI, S3 and our scheme respectively. Exponential empirical relationships have been tried to be employed to attain improvements in prediction of snow cover followed by a test of correlation between true and theoretical fractional snow cover values. An improvement in degree of correlation is obtained over the conventional methodologies which serves for the verification of scheme employed and empirical relationship defined, collectively. The results provide a scope for improvements and investigations in the subject of fractional snow cover mapping.
\end{abstract}

\section{Keywords}

NDSI, S3, Fractional Snow Mapping

\section{Introduction}

Local and global energy routines are prominently affected by variation in snow cover. The environmental problems encompassing global warming conditions 
require expeditious problem-solving efforts. Snow, permafrost and ice form an energetic part of the cryospheric system. The reflective land cover is regulating the temperature of earth from millions of years. While operationalizing geographical sustainability, snow melt is the source of water for irrigation and drinking reasons. Moisturizing soil may prove to be added advantage for reducing risks of wildfire occurrences. A synergy of contributions between the research and industrial communities proffer a plausible means of solving the problem in general. Interactive visual analysis of satellite imageries calls for continuous meticulous enhancements to alleviate the delineations of land cover classes in snow maps. Actively indicating variations in global phenomenon significance of cryospheric studies have increased concerns due to the rate of climate change.

The water resources in the Himalayan ranges are under increasing demographic pressure superfluous with continuous changes in climate, economics and development. Most of the downstream hydrological processes are regulated by variability of snow dynamics in the Himalayas [1] [2]. Snowpacks have had been the prominent source of surface and ground water since ages. Hence snow cover variation acts as an important terrestrial phenomenon. The insulating and reflecting properties of snow affects temperature regime of the earth. A thin zone of soil is also responsible for sustainment of living organisms under the permafrost. Hence the problem of mapping snow cover to accurate extents gains prominence with the problem of global climate change. Performing predictions about the global snow cover employing the current extent of snow requires continuous improvements in mapping algorithms. Fighting the problem on a global scale requires accurate interpretation of data. In-situ measurements can be applied over limited regions for specific periods of time. Hence analysis is considered over remote satellite images which promise the regularity and consistency of operations. The acquisitions collected over the satellite imageries face the constraints of satellite imaging problems such as DN distortions, row skips, and cloud cover. Preserving the accuracy of mapping requires fine delineating capabilities. Further, the extents of snow mapping are considerably subjected to errors of omission and errors of commission under varying complexities of forest cover (canopy coverage), debris mingling, topography and limitations of resolutions of sensors scanning the coverage. Apart from the protective characteristics, extensive disasters are also encompassed under snow dynamics and related activities. Snow blizzards, avalanches, heavy snow falls, etc. call for better mapping of snow covered regions. The paper is organized as follows: The related research work is highlighted in Section 2. Data used and study area is described in Section 3. Details of the methodology and related research text are illustrated in Section 4 followed by presentation of results in Section 5. Future diagnoses related to current work and in general, are outlined in Section 6.

\section{Related Research Work}

Remote sensing is now increasingly being used to monitor snow cover changes 
[3] over large scale and improved resolution proving to be one of the effective and practical means for snow cover information procurement with a few improvements under cloud cover. Apart from the optical and multispectral observations distinguished efforts under microwave remote sensing have also come to the head due to high penetration and moisture observation capabilities proving necessary supplementary data to optical means [4] [5] [6]. Recent attempts to measure the snow cover in the study area include [3] [7] [8] [9]. Famous Karakoram anomaly [10] is a mentionable fact highlighting the importance of investigation o micro topographical and climatic effects in the young Himalayas. Local and sub-regional studies include [4] [9] [11]-[17].

In the recent times many efforts have been made to work upon the algorithms using MODIS data to obtain various snow cover products [18] [19] [20] [21]. Works suggest that multi-temporal synthesis of the products can lessen the persistent problem of cloud occurrence. Increasing the time of synthesis can improve the quality of results but sacrifices the well-timed delivery of products. [18] [22] highlight the efforts in this direction taking the height factor into account for removal of cloud cover. [23] developed a scheme to delineate dry from wet in the Indian part of Himalayas. Decoupling snowmelt from vegetation has also been tried to improvise through improved indices [24] [25] [26].

Dependable information on the state of information regarding global snow cover has increasingly found its relation with climate change studies [27] [28] [29] [30]. In the past two decades, a series of influential works related to snow cover estimation for long and short period durations have been conducted. The prevalent techniques include employment of multispectral bands, individual fractional abundances on basis of spectral signatures and relative end member spectral mixture analysis [31]-[37]. A detailed account of remote sensing techniques to study snow cover is provided in [20] have been among the foundation stones for providing methodologies for snow cover mapping and analysis. Various MODIS related studies may make the use of MODIS water products as such MOD44W to filter out the water bodies in the snow mappings [38] while some studies require pre-masking of water bodies [39]. The work attempts to query the expansions in snow index structures and conventional methodologies while investigating the scope of enhancement in predicting the snow extents over the study area.

\section{Data used and Study Area}

\subsection{Landsat and MODIS Data}

Landsat series holding one of the longest fine resolution data ( $>35$ years) form the choice of our dataset. Landsat 8 was launched on February 11, 2011 having two sensors namely Operational Land Imager (OLI) and Thermal Infrared Sensor (TIRS). Collecting images in Worldwide Reference System-2 (WRS2) the accession of images is performed in a 16 day repeat cycle at an approximate scene size of $170 \mathrm{~km}$ (north to south) by $183 \mathrm{~km}$ (east to west). TIRS images are provided at same resolution as visual band images i.e. $30 \mathrm{~m}$ although they are cap- 
tured at $100 \mathrm{~m}$. Our dataset covers features from OLI and TIRS sensors covering 8 spectral bands in all geocoded over UTM north zone 44 WGS84 datum.

MOD021KM and MOD09GA MODIS (Moderate Resolution Imaging Spectroradiometer) Terra science datasets are employed. MOD09GA is an L2G (level 2 gridded) daily surface reflectance MODIS product providing spectral surface reflectance on earth corrected for atmospheric gasses and aerosols. One day repeat image for wavelength range 0.4 to 2.1 is used corresponding to MODIS bands 1 - 7. Calibrated, geolocated, at-aperture radiance values for higher bands required in the study is obtained from MOD021KM SDS (science dataset). MOD021KM is a level $1 \mathrm{~B}$ dataset which contains 36 band corrected and geolocated radiance information over $0.4 \mu \mathrm{m}-14.4 \mu \mathrm{m}$ range. Quality control is maintained by superfluous error estimates and quality flags. Band 31 data from MODIS spectrum is obtained during night time.

\subsection{Study Area}

A subset of WRS2 Landsat scene path-147, row-37 covering a region of Himachal Pradesh and Jammu Kashmir is chosen for the development and testing of the reconstructions introduced to the conventional snow index designs. The scene is chosen for the existence of topographical variations as well as extensive snow cover. Irregular topography introduces heterogeneity in snow cover encompassing the issues of IMD (Ice mixed debris) and snow/ice under shadow. The problem of underestimating snow cover persists in such a region.

\section{Methodology}

\subsection{Normalized Difference Snow Index (NDSI)}

NDSI has the reputation of being among the most prominent methodologies for providing the research community with a foundation snow mapping scheme. It's been over a decade since the successful continuous usage of NDSI making up a detailed set of studies. The chief functionality of separating snow from optically similar responsive cloud lies under the successful employment of NDSI in a multitude of studies.

$$
\text { NDSI }=(\text { Green }- \text { SWIR }) /(\text { Green }+ \text { SWIR })
$$

Spectral response of snow is low in SWIR band (short wave infrared band) while high in visible green region. The same property is made use of, on the basis of cloud cover spectral response being higher in both the spectral regions. Particularly Cumulus clouds show the expected behaviour in exercise. A value of 0.4 stands to be consistent in thresholding snow cover from other land cover types. Generally the problem of ambiguous snow cover determination arises due to mixing with water which is eliminated with added criteria of reflectance under NIR band (near infrared band).

\subsection{S3 Snow Index}

Individual spectral response of vegetation and snow is accounted for in the 
structure and exercise of S3 snow index. Operation of NDSI is often accompanied by criteria thresholding of the results associated with a certain percentage of reflectance in NIR band.

$$
\mathrm{S} 3=(\mathrm{NIR} *(\operatorname{Red}-\mathrm{SWIR})) /(\mathrm{NIR}+\mathrm{Red})(\mathrm{NIR}+\mathrm{SWIR})
$$

S3 serves to classify snow from vegetation identifying a gain over NDSI particularly in the regions where the vegetation/forest cover is snow laden, while retaining the cloud discrimination behaviour. A threshold of 0.1 has been found to be suitable for a universal functionality of S3.

\subsection{Incorporation of Thermal Band $(11.0 \mu \mathrm{m})$}

A modest normalization scheme including the thermal band in the range of $10.60 \mu \mathrm{m}$ to $11.20 \mu \mathrm{m}$ is seen to retain the characteristics of vegetation and cloud discrimination empirically. Classification of snow with random chances of mixed pixels with water is conducted well by NDSI but the response of similar land cover classes like frozen lakes is not clearly identified by NDSI as well as S3.

New thermal index $=$ Red - Thermal Infrared/Red + Thermal Infrared

Unique spectral behaviour of snow, water, cloud and similar land cover types is made use of in clearly identifying snow cover from rest of the classes. Particularly the snow extent which might be superficially logical but actually wrong is filtered out with the incorporation of thermal band in snow index design. The regions of frozen glacial lakes and water bodies are extracted out well with the help of this scheme while staying true to correctly classifying the snow pixels. Streams of water the surroundings of which are seen to be covered with snow are correctly identified as water, showing an advantage of incorporation of thermal band in the snow index schemes.

\subsection{Approach Followed in Workflow}

The fractional snow cover obtainable from the Landsat images calls for errorfree snow mapping of Landsat scenes. Fractional count of snow covered pixels from the MODIS image overlaying Landsat scene can be obtained in one of the two ways. First method requires registering MODIS image with the Landsat scene and coarsening the resolution of Landsat up to the size of MODIS pixels. The other way is finding out the number of corresponding pixels of Landsat in a MODIS pixel. Fractional snow count in Landsat followed by fractional snow count in MODIS can also be effectuated, but we try to follow a computationally expedient approach of binary snow count in Landsat followed by fractional snow count in MODIS. A binary snow mapping technique often categorizes a pixel as snow if has more than half snow occupancy while classifying it as non-snow if it has less than half of the area covered by snow. Generally at the higher elevations the regions predominantly covered by snow are realized as snow under the limitations of resolution and algorithm worked upon. Similarly some regions covering traces of snow remain completely classified under non-snow class leaving the 
accountability of the minor snow extents.

The binary algorithm of snow mapping requires a certain threshold above which the pixels are classified as snow. The threshold is achieved through the means of computing the trough of frequency distribution curve for index values of all the pixels. The trough generally signifies a value of demarcation between two land cover classes with varying position and amplitude as per the choice of application of land cover index. A rectangular ROI covering about 85\% Landsat scene extent is masked out from the each MOD09GA feature. Registration of MODIS and Landsat pixels with their original resolutions is a matter of accuracy maintained in manually fixating corresponding tie points. Since the MOD09GA is initially re-projected from sinusoidal projection to the same zone of Landsat scene the errors in registration are only the inherent ones. Next operation of overlaying is completed by resampling MODIS pixel to $480 \mathrm{~m} \times 480 \mathrm{~m}$ so as to finely cover $16 \times 16$ Landsat pixels of $30 \mathrm{~m} \times 30 \mathrm{~m}$ resolution. Nearest neighbourhood resampling operation is employed to prolong the original DN values down the line of further operations. $320 \times 320$ pixel ROI is masked out from MOD09GA layers overlaying exactly over $5120 \times 5120$ Landsat pixels. Next step comprises of application of snow cover indices over the corresponding image pairs. It is followed by threshold evaluation for each index resulting in the binary snow/non-snow image pairs. Threshold detection resulting in the binary image is then followed by reduction of Landsat snow/non-snow binary image to Landsat fractional snow image at the resolution of MODIS pixel. The reduction is maintained with the boundaries of MODIS boundaries of pixels with subsequent extraction of index values and fractional snow/non-snow values from MODIS images and Landsat fractional images.

Focusing on the nature of relationship between index and fraction values statistical associations between the two is examined and developed to attain an empirical relationship rather than a factual one. Initially a correlation value between the two is sought followed by an assorted test of statistical relationships. Three regression relationships are tested for prediction analysis viz.: a) Relation 1: Linear statistical relationship; b) Relation 2: Polynomial function relationship; and c) Relation 3: Sinusoidal relationship. Additional parameters regulating goodness of fit are measured for critique. Quantifications of root mean squared error (RMSE), coefficient of determination $\left(\mathrm{R}^{2}\right)$ and sum of squares of error (SSE) are obtained for each relationship for every index. Though the alterations are present in literature the parameter to be predicted i.e. snow cover is taken as dependent variable while obtaining the relationships. Once the parameter measurements are obtained in the stage of development the test of the index design as well as the empirical relationship is carried out. The relationship between the actual fractional snow/non-snow cover and theoretical cover is assessed and the proportion of similarity is obtained. Higher the degree of similarity between the two greater the reliability of prediction down the index-empirical relation set. 


\section{Results and Discussions}

Correlation coefficient values between the corresponding regions of Landsat fractional image and MODIS index image are shown in Table 1. In totality the values lie in the range of $77 \%$ to $85 \%$. For NDSI $95 \%$ Confidence Interval (CI) of the Pearson's correlation coefficient translated to correlation value existing within the sample population of the bivariate values lies in the range [0.768, 0.772]. Similarly, for S3 and the new thermal index 95\% CI values lie in the range $[0.786,0.790]$ and $[0.849,0.854]$ (reported up to 3 decimal places due to close gaps in the lower and upper limit). The CI values correspond to actual correlation values shown in Table 1. Based on the values employed in the first stage of analysis (index value-fractional snow/non-snow count correlation) relational models are tested over which the goodness of fit parameters are observed (see Table 2). Figures 1-3 show the manner of variation of supporting fitness parameters of all the index-model pairs. $\mathrm{R}^{2}$, SSE and RMSE values are in logical consistency with the obtained results. The minimal difference between the cor-

Table 1. Correlation figures between index values and fractional snow/non-snow values. Each MOD09GA and MOD021KM pixels holds an index value after threshold decision. Correspondingly Reduced Fractional Landsat image holds the fractional snow count value. MODIS and Landsat datasets are overlaid each other congruently to find the Pearson's Correlation Coefficient.

\begin{tabular}{cc}
\hline Snow index & Correlation value (\%) \\
\hline NDSI & 77.04 \\
S3 & 78.82 \\
New thermal index & 85.15 \\
\hline
\end{tabular}

Table 2. Relational models parameterized with goodness of fit.

\begin{tabular}{lccc}
\hline \multirow{2}{*}{ Relational model } & \multicolumn{3}{c}{ Statistical relationship } \\
\cline { 2 - 4 } & RMSE & SSE & $\mathrm{R}^{2}$ \\
\hline Relation 1 & 0.22 & NDSI & 0.60 \\
Relation 2 & 0.19 & 250.77 & 0.72 \\
Relation 3 & 0.19 & 176.26 & 0.72 \\
& & 175.47 & 0.63 \\
\hline Relation 1 & 0.21 & 231.9 & 0.71 \\
Relation 2 & 0.18 & 178.7 & 0.71 \\
Relation 3 & 0.18 & 178.2 & \\
\hline Relation 1 & & S3 thermal index & 0.72 \\
Relation 2 & 0.17 & 36.77 & 0.72 \\
Relation 3 & 0.17 & 36.23 & 0.72 \\
\hline
\end{tabular}




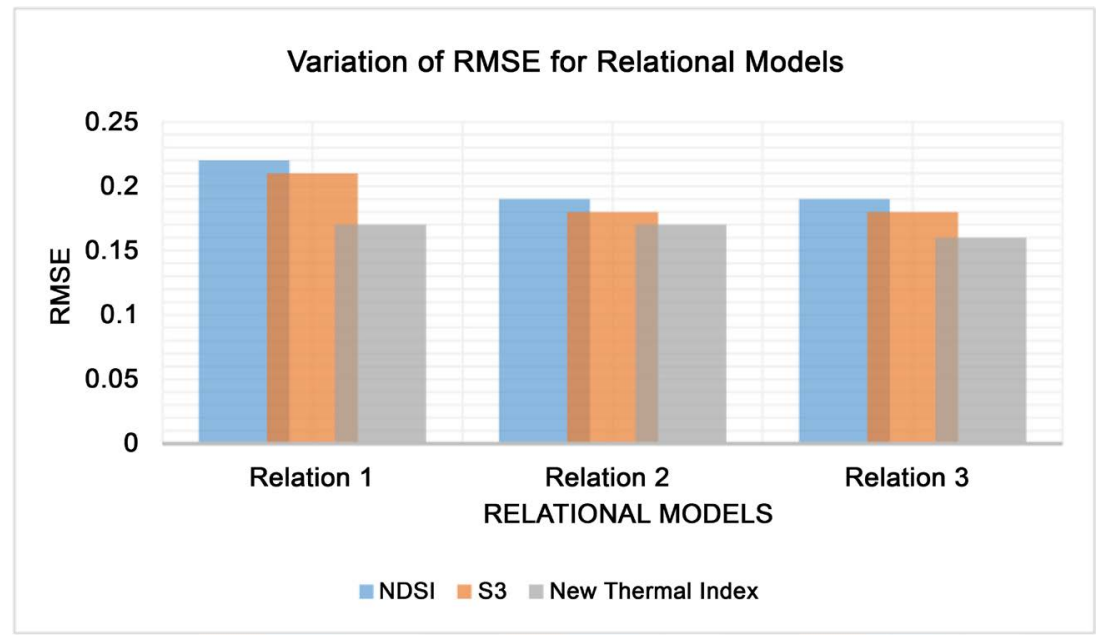

Figure 1. The values of RMSE depicting the implementation of index-fractional snow count for: (a) NDSI; (b) S3; and (c) New Thermal Index.

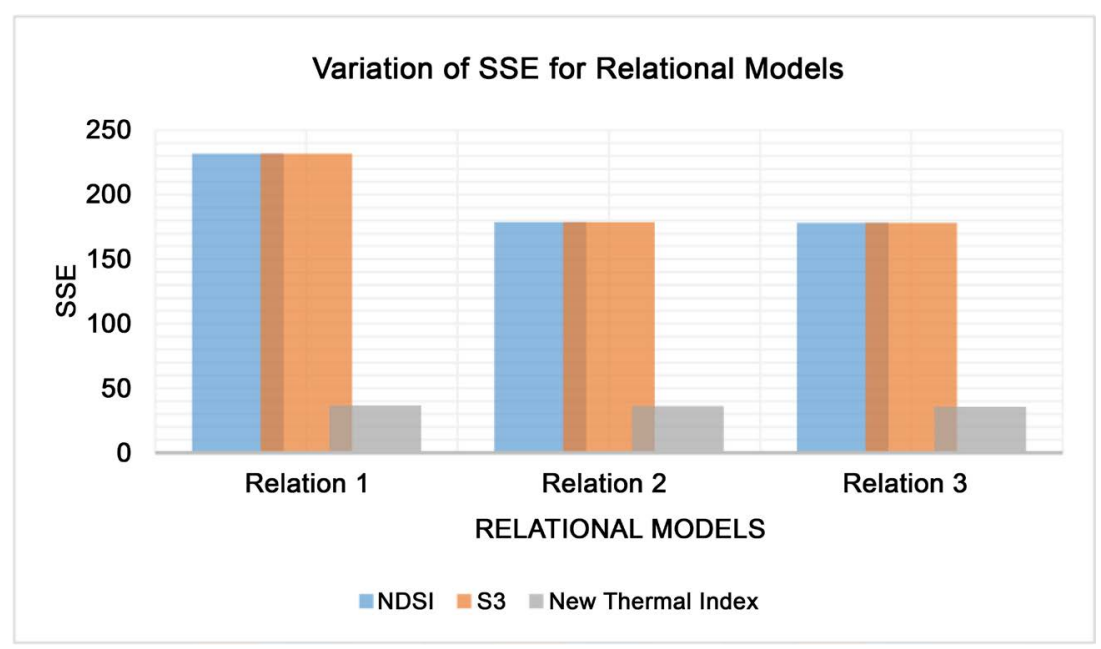

Figure 2. The values of SSE depicting the implementation of index-fractional snow count for: (a) NDSI; (b) S3; and (c) New Thermal Index.

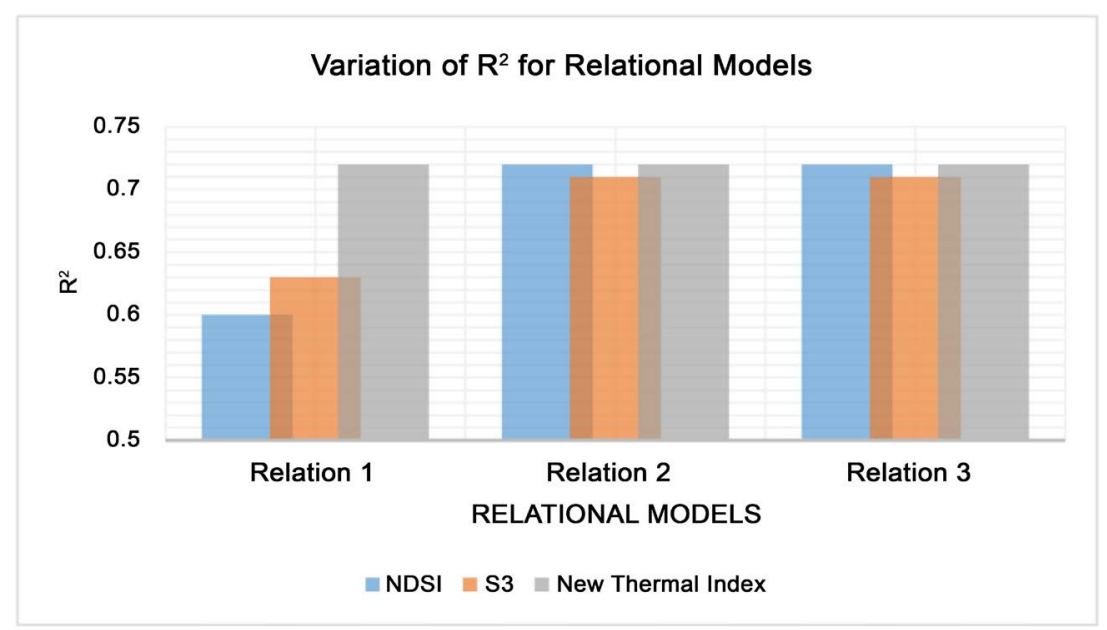

Figure 3. The values of RMSE depicting the implementation of index-fractional snow count correlation for: (a) NDSI; (b) S3; and (c) New Thermal Index. 
Table 3. Relation model test for development region between predicted and actual values.

\begin{tabular}{cc}
\hline & Correlation value (\%) \\
\cline { 2 - 2 } Relational model & NDSI \\
\hline Relation 1 & 72.50 \\
Relation 2 & 80.65 \\
Relation 3 & 80.81 \\
\hline Relation 1 & S3 \\
Relation 2 & 74.00 \\
Relation 3 & 80.50 \\
& 80.65 \\
\hline Relation 1 & 86.60 \\
Relation 2 & 87.40 \\
Relation 3 & 87.52 \\
\hline
\end{tabular}

relation values is suggested by a standard deviation of 4.26. As per the resolution of images in MOD09GA and MOD021KM if "a" number of entries are fitted under the various relational models for the former, "a/2" number of the same are adjusted for latter. The appraisal of the statistical relational models on the lines of linear adjustments shows the outweighing factor of the new index design relatively with NDSI and S3 indices. $\mathrm{R}^{2}$ values are seen to support the assertion. The values are continuously increasing from NDSI, S3 to the new scheme as well from Relation 1 to Relation 3. Relation 3 marginally provides better statistics. Functioning of polynomial and sinusoidal relations is seen to work in coherence with the obtained results for traditional linear relationships.

When the index values are developed for the whole test region the testing is performed to examine the strength of prediction of index-relational model pair. Correlation between the achieved and real fractional snow/non-snow values suggest outperformance of new scheme w.r.t to NDSI and S3. Here the magnitude of similarity between the actual Landsat fractional count and predicted results is found out (see Table 3). Relational models 2 and 3 are seen to increase the strength of prediction whether the predicted value is high or low.

\section{Conclusion and Future Prospects}

In this work, a snow mapping scheme was proposed where the prominent segment was incorporation of a thermal band into the structure of a snow index design and development of a fractional snow matching method. MODIS datasets MOD09GA, MOD021KM and Landsat OLI/TIRS datasets were used in this study. The degree of similarity obtained between the index values and the calculated fractional snow count values was high for the scheme developed with respect to the existing methods. Sinusoidal relational model coupled with the new thermal index provided improvements in fractional snow cover delineation. The 
same scheme when employed to predict snow count per pixel in MODIS images followed coherence. Prediction was tested over subset regions where the coefficients of relational model were derived from a weighted average of two other subsets. Testing over smaller regions took into account a possible bias for homogeneity for all the indices and proved that the new scheme performs competently. The degree of similarity between the predicted and actual fractional snow count per pixel was maximum for the developed method.

Further performance of the method can be evaluated by the application of same over extended regions. Fine resolutions data can provide a means of such assessment. With regard to a computational limitation the procedure of congruently overlaying the MODIS and Landsat images needs to be regularized. The operation of realizing and finalizing the results needs to be coherent, which is still articulate.

It is to be noted that the dependency of snow mapping techniques still lies with traditional index-thresholding methods and the ones indirectly based on them with adjunct functionalities. Introduction of better accuracy with increased resolution of satellite imageries, improved meticulous knowledge of spectral behaviour of land cover classes, or in situ information, call for increase in the delivery time of snow cover products. Hence the work over formulation of design of snow delineation methods, threshold evaluation techniques and prediction of snow content per pixel continues to hold a potential and needs to be worked upon for delivering reliable results speedily. By the time the real-time-user dependency lies with the index thresholding methods, the question of finding better possibilities in this direction needs be investigated. The results obtained in this work can be leveraged to introduce improvements in the current snow mapping techniques at the regional or broader levels.

\section{References}

[1] Viviroli, D., Dürr, H.H., Messerli, B., Meybeck, M. and Weingartner, R. (2007) Mountains of the World, Water Towers for Humanity: Typology, Mapping, and Global Significance. Water Resources Research, 43, 1-13. https://doi.org/10.1029/2006WR005653

[2] Dettinger, M. (2014) Impacts in the Third Dimension. Nature Geoscience, 7, 166-167. https://doi.org/10.1038/ngeo2096

[3] Immerzeel, W.W., Droogers, P., de Jong, S.M. and Bierkens, M.F.P. (2009) Large-Scale Monitoring of Snow Cover and Runoff Simulation in Himalayan River Basins Using Remote Sensing. Remote Sensing of Environment, 113, 40-49. https://doi.org/10.1016/j.rse.2008.08.010

[4] Jiancheng, S., et al. (2012) Progresses on Microwave Remote Sensing of Land Surface Parameters. Science China Earth Sciences, 55, 1052-1078. https://doi.org/10.1007/s11430-012-4444-x

[5] Dozier, J. (1997) Mapping Seasonal Snow with SIR-C/X-SAR in Mountainous Areas. Techniques, 59, 294-307.

[6] Nagler, T. and Rott, H. (2000) Retrieval of Wet Snow by Means of Multitemporal SAR Data. IEEE Transactions on Geoscience and Remote Sensing, 38, 754-765. 
[7] Shrestha, A.B. and Joshi, S.P. (2009) Snow Cover and Glacier Change Study in Nepalese Himalaya Using Remote Sensing and Geographic Information System. Journal of Hydrology and Meteorology, 6, 26-36.

[8] Basnett, S. and Kulkarni, V. (2012) Monitoring of Seasonal Snow Cover in Sikkim Himalaya Using Remote Sensing Techniques. Climate Change in Sikkim Patterns, 101, 69-80.

[9] Maskey, S., Uhlenbrook, S. andOjha, S. (2011) An Analysis of Snow Cover Changes in the Himalayan Region Using MODIS Snow Products and in-situ Temperature Data. Climatic Change, 108, 391-400. https://doi.org/10.1007/s10584-011-0181-y

[10] Tahir, A.A., Chevallier, P., Arnaud, Y., Ashraf, M. and Bhatti, M.T. (2015) Snow Cover Trend and Hydrological Characteristics of the Astore River Basin (Western Himalayas) and Its Comparison to the Hunza Basin (Karakoram Region). Science of the Total Environment, 505, 748-761. https://doi.org/10.1016/j.scitotenv.2014.10.065

[11] Zhang, Y., Li, T. and Wang, B. (2004) Decadal Change of the Spring Snow Depth over the Tibetan Plateau: The Associated Circulation and Influence on the East Asian Summer Monsoon. Journal of Climate, 17, 2780-2793. https://doi.org/10.1175/1520-0442(2004)017<2780:DCOTSS >2.0.CO;2

[12] Qin, D.H., Liu, S.Y. and Li, P.J. (2006) Snow Cover Distribution, Variability, and Response to Climate Change in Western China. Journal of Climate, 19, 1820-1833. https://doi.org/10.1175/JCLI3694.1

[13] Zhang, Y., Yan, S. and Lu, Y. (2010) Snow Cover Monitoring using MODIS Data in Liaoning Province, Northeastern China. Remote Sensing, 2, 777-793. https://doi.org/10.3390/rs2030777

[14] Jin, X., Ke, C.-Q., Xu, Y.-Y. and Li, X.-C. (2015) Spatial and Temporal Variations of Snow Cover in the Loess Plateau, China. International Journal of Climatology, 35, 1721-1731. https://doi.org/10.1002/joc.4086

[15] Singh, S.K., Rathore, B.P., Bahuguna, I.M. and Ajai (2014) Snow Cover Variability in the Himalayan-Tibetan Region. International Journal of Climatology, 34, 446-452. https://doi.org/10.1002/joc.3697

[16] Jain, S.K., Goswami, A. and Saraf, A.K. (2009) Role of Elevation and Aspect in Snow Distribution in Western Himalaya. Water Resources Management, 23, 71-83. https://doi.org/10.1007/s11269-008-9265-5

[17] Sharma, V., Mishra, V.D. and Joshi, P.K. (2012) Snow Cover Variation and Streamflow Simulation in a Snow-Fed River Basin of the Northwest Himalaya. Journal of Mountain Science, 9, 853-868. https://doi.org/10.1007/s11629-012-2419-1

[18] Wang, J., et al. (2014) Remote Sensing for Snow Hydrology in China: Challenges and Perspectives. Journal of Applied Remote Sensing, 8, 84687. https://doi.org/10.1117/1.JRS.8.084687

[19] Xie, H. (2009) Development and Assessment of Combined Terra and Aqua Snow Cover Products in Colorado Plateau, USA and Northern Xinjiang, China. Journal of Applied Remote Sensing, 3, 33559. https://doi.org/10.1117/1.3265996

[20] Hall, D.K., Riggs, G.A., Foster, J.L. and Kumar, S.V. (2010) Development and Evaluation of a Cloud-Gap-Filled MODIS Daily Snow-Cover Product. Remote Sensing of Environment, 114, 496-503. https://doi.org/10.1016/j.rse.2009.10.007

[21] Dietz, A.J., Kuenzer, C., Gessner, U. and Dech, S. (2012) Remote Sensing of Snow-A Review of Available Methods. International Journal of Remote Sensing, 33, 4094-4134. https://doi.org/10.1080/01431161.2011.640964 
[22] Parajka, J., Pepe, M., Rampini, A., Rossi, S. and Blöschl, G. (2010) A Regional Snow-Line Method for Estimating Snow Cover from MODIS during Cloud Cover. Journal of Hydrology, 381, 203-212. https://doi.org/10.1016/j.jhydrol.2009.11.042

[23] Gupta, R.P., Haritashya, U.K. and Singh, P. (2005) Mapping Dry/Wet Snow Cover in the Indian Himalayas using IRS Multispectral Imagery. Remote Sensing of Environment, 97, 458-469. https://doi.org/10.1016/j.rse.2005.05.010

[24] Delbart, N., Kergoat, L., Le Toan, T., Lhermitte, J. and Picard, G. (2005) Determination of Phenological Dates in Boreal Regions using Normalized Difference Water Index. Remote Sensing of Environment, 97, 26-38. https://doi.org/10.1016/j.rse.2005.03.011

[25] Delbart, N., Le Toan, T., Kergoat, L. and Fedotova, V. (2006) Remote Sensing of Spring Phenology in Boreal Regions: A Free of Snow-Effect Method using NOAA-AVHRR and SPOT-VGT Data (1982-2004). Remote Sensing of Environment, 101, 52-62. https://doi.org/10.1016/j.rse.2005.11.012

[26] Hudson Dunn, A. and de Beurs, K.M. (2011) Land Surface Phenology of North American Mountain Environments using Moderate Resolution Imaging Spectroradiometer Data. Remote Sensing of Environment, 115, 1220-1233. https://doi.org/10.1016/j.rse.2011.01.005

[27] Foley, J.A., et al. (2005) Global Consequences of Land Use. Science, 309, 570-574.

[28] Boysen, L.R., et al. (2014) Global and Regional Effects of Land-Use Change on Climate in 21st Century Simulations with Interactive Carbon Cycle. Earth System Dynamics, 5, 309-319. https://doi.org/10.5194/esd-5-309-2014

[29] Foley, J.A., et al. (2002) Global Land Cover Mapping from MODIS: Algorithms and Early Results. Remote Sensing of Environment, 83, 287-302.

[30] Foley, J.A., et al. (2010) MODIS Collection 5 Global Land Cover: Algorithm Refinements and Characterization of New Datasets. Remote Sensing of Environment, 114, 168-182. https://doi.org/10.1016/j.rse.2009.08.016

[31] Hall, D.K., Riggs, G.A. and Salomonson, V.V. (1995) Development of Methods for Mapping Global Snow Cover using Moderate Resolution Imaging Spectroradiometer Data. Remote Sensing of Environment, 54, 127-140. https://doi.org/10.1016/0034-4257(95)00137-P

[32] Hall, D.K., Riggs, G.A., Salomonson, V.V., DiGirolamo, N.E. and Bayr, K.J. (2002) MODIS Snow-Cover Products. Remote Sensing of Environment, 83, 181-194. https://doi.org/10.1016/S0034-4257(02)00095-0

[33] Rosenthal, W. and Dozier, J. (1996) Automated Mapping of Montane Snow Cover at Subpixel Resolution from the Landsat Thematic Mapper. Water Resources Research, 32, 115-130. https://doi.org/10.1029/95WR02718

[34] Painter, T.H., Roberts, D.A., Green, R.O. and Dozier, J. (1998) The Effect of Grain Size on Spectral Mixture Analysis of Snow-Covered Area from AVIRIS Data. Remote Sensing of Environment, 65, 320-332. https://doi.org/10.1016/S0034-4257(98)00041-8

[35] Dozier, J., Green, R.O., Nolin, A.W. and Painter, T.H. (2009) Interpretation of Snow Properties from Imaging Spectrometry. Remote Sensing of Environment, 113, S25-S37.

[36] Vikhamar, D. and Solberg, R. (2003) Subpixel Mapping of Snow Cover in Forests by Optical Remote Sensing. Remote Sensing of Environment, 84, 69-82. https://doi.org/10.1016/S0034-4257(02)00098-6

[37] Shreve, C.M., Okin, G.S. and Painter, T.H. (2009) Indices for Estimating Fractional 
Snow Cover in the Western Tibetan Plateau. Journal of Glaciology, 55, 737-745. https://doi.org/10.3189/002214309789470996

[38] Carroll, M.L., Townshend, J.R., DiMiceli, C.M., Noojipady, P. and Sohlberg, R.A. (2009) A New Global Raster Water Mask at $250 \mathrm{~m}$ Resolution. International Journal of Digital Earth, 2, 291-308. https://doi.org/10.1080/17538940902951401

[39] Tateishi, R., Hoan, N.T., Kobayashi, T., Alsaaideh, B., Tana, G. and Phong, D.X. (2014) Production of Global Land Cover Data-GLCNMO2008. Journal of Geography and Geology, 6, 99. https://doi.org/10.5539/jgg.v6n3p99 